\title{
Demonstratives and non-embedded nominalisations in three Papuan languages of the Timor-Alor-Pantar family
}

\author{
Antoinette Schapper and Lila San Roque \\ Leiden University / Max Planck Institute for Psycholinguistics
}

\begin{abstract}
This paper explores the use of demonstratives in non-embedded clausal nominalisations. We present data and analysis from three Papuan languages of the Timor-Alor-Pantar family in south-east Indonesia. In these languages, demonstratives can apply to the clausal as well as to the nominal domain, contributing contrastive semantic content in assertive stance-taking and attention-directing utterances. In the Timor-Alor-Pantar constructions, meanings that are to do with spatial and discourse locations at the participant level apply to spatial, temporal and mental locations at the state or event level.
\end{abstract}

Keywords: non-embedded nominalisations; demonstratives; Timor-Alor-Pantar languages; Papuan languages.

\section{Introduction}

In handbooks and the typological literature, demonstratives are identified as elements of entity-referring expressions that are used to locate objects in physical space or a discourse-based linguistic context. Functional characterisations of demonstratives remark that they "point to an object" (Dixon 2003), and "serve to identify concrete referents" (Burenhult 2008). Syntactic characterisations of demonstratives place them in the nominal domain, the prototypical grammatical means for referring to entities. For instance, Himmelmann (1997:3) writes: "Als Demonstrativa werden gemeinhin lokaldeiktische Elemente bezeichnet, die pronominal [...] oder adnominal [...] verwendet werden können" (italics original). ${ }^{1}$ In this paper, we discuss the non-referential use of demonstratives in non-embedded nominalisations (NENs), where they have scope over independent clauses to encode spatial, temporal and epistemic (i.e., knowledge-related) information about events and situations. ${ }^{2}$ This phenomenon has, until recently, gone largely untreated in the typological literature. 
The aims of this paper are:

i. to add to the typology of non-embedded nominalisations. Using data from a little-known group of Papuan languages of the Timor-Alor-Pantar (TAP) family, we exemplify the contrastive use of whole paradigms of demonstratives in forming NEN constructions;

ii. to explore the functions of demonstratives with clausal as opposed to nominal scope, supporting current trends in demonstrative theory that emphasise clusterings of space-time-knowledge meanings.

In $\$ 2$ we introduce non-embedded nominalisations and point to their occurrence in languages from diverse parts of the world. We describe the different types of nominalising morphemes that are used in forming NENs and summarise meanings and pragmatic functions that are typically associated with them. This provides the background essential for understanding the contribution that TAP languages make to the typology of NENs.

In $\$ 3$ we look in detail at certain members of the TAP family, where understanding non-embedded nominalisation requires consideration of demonstrative meanings. In these TAP languages, each member of the demonstrative paradigm can be used to form a NEN. Different demonstratives contrast with one another when used with scope over a clause, paralleling their use in the more prototypically nominal domain of concrete reference. Meanings that have to do with the spatial and discourse locations of referents expressed as simple NPs apply to the spatial, temporal and mental locations of events or situations that are expressed as nominalised clauses.

Section 4 concludes our discussion of how the TAP demonstrative-based NENs contribute to the general typology of NENs and our understanding of demonstrative meaning. Non-embedded nominalisations reveal a clustering of structural, semantic and pragmatic properties across unrelated languages. The applicability of demonstratives to clauses in TAP languages highlights relationships between spatial, temporal, and epistemic configurations in the speech event, and concurs with recent findings that de-emphasise space as the most significant parameter in demonstrative use.

\section{Non-embedded nominalisations}

\subsection{Overview}

A "non-embedded nominalisation" (Matisoff 1972) is a "nominalised clause which is not syntactically or functionally an element of any higher 'matrix' clause, but 
which functions as a complete and independent utterance" (Genetti 2011:178). We use the term "nominalised clause" quite generally to mean a verbal clause that is marked by a free or bound morpheme that is usually diagnostic of a nominal phrase in the language in question, and has clausal nominalisation as at least one of its functions. ${ }^{3}$ In this paper we look only at nominalisation structures where the clause retains sentence syntax, as opposed to being assimilated to noun phrase syntax, for example, by subjects becoming possessors (see Comrie and Thompson 2007).

Non-embedded nominalisations are most richly described and discussed in regard to the "versatile nominalisations" (Noonan 1997) of many Tibeto-Burman languages (concerning early treatments of the phenomena, see DeLancey 2011). Bickel (1999) proposes that a feature of the "Standard Sino-Tibetan Nominalisation" pattern is that nominalised clauses can be "stand alone" utterances, rather than explicitly embedded clauses. Examples (1)-(3) illustrate non-embedded nominalisation in Chantyal. ${ }^{4}$ In example (1), the verb ci- 'sit' is inflected for perfective aspect and heads an independent verbal clause. Example (2) shows an embedded clause headed by ci- 'sit' and nominalised with -wa 'NMLZ'. Example (3) shows a non-embedded nominalisation: the clause is "nominalised" in that $c i$ - 'sit' is marked with -wa 'NMLZ', but the sentence is independent, not an embedded structure in a matrix clause.

(1) Ra phiri them-ay na kha-i ci-i. and again house-LOC TOP come-ANT sit-PFV 'And again (I) came home, and (I) stayed.' (Noonan et al. 1999:547)

(2) Kadmandu-ri ci-wa pari-i to Kathmandu-LOC sit-NMLZ happen-PFv FACT

'(I) must stay in Kathmandu.' (Noonan 2006:21-22)

(3) Ci-wa do sit-NMLZ FACT

'(I’ll) stay!' (Noonan 1997:7)

Non-embedded nominalisations that retain sentence syntax are widely reported and discussed for many Tibeto-Burman languages, for example Belhare (Bickel 1999), Dolakha Newar (Genetti 2007), Manange (Hildebrandt 2004), Chantyal (Noonan 1997), Kathmandu Newar (Hargreaves 2005), and Lahu (Matisoff 1972), and for languages of East Asia, such as Japanese and Korean (Horie 2011, Simpson and Wu 2001). They are present in several Austronesian languages, for example, Malagasy (Potsdam 2011), depending on how certain nominal exclamatives are analysed, and several eastern varieties of colloquial Malay (using punya 'poss' or ini 'this', Schapper fieldnotes; see also Yap 2011). Non-embedded nominalisations have also been reported in unrelated languages in the Americas 
(e.g., Yupik Eskimo, Woodbury 1985; Hup, Epps 2009) and in New Guinea (e.g., Usan, Reesink 1987; Duna, San Roque 2008).

As pointed out in several studies (Epps 2008; Horie 2008, 2011; San Roque 2008; Yap and Grunow-Hårsta 2010), non-embedded nominalisation is related to insubordination, "the conventionalised main clause use of what, on prima facie grounds, appear to be formally subordinate clauses" (Evans 2007:367). In both cases, what would be expected to be an embedded or otherwise dependent structure is used independently as a complete utterance. A major function of insubordination identified by Evans (2007) that is also typical of non-embedded nominalisation is expressing "modal frames" (e.g., exclamation, epistemic attitude), discussed further in $\$ 2.3$.

\subsection{Nominalising morphemes in NENs}

A typologically significant feature common to non-embedded nominalisations in the Timor-Alor-Pantar languages discussed here $(\$ 4)$ is the productive use of a full paradigm of contrastive demonstratives to mark the nominalised clause (see also Kratochvíl 2011: 789). In relation to this feature, in this section we provide background on the variety of nominalising morphemes that are attested in nonembedded nominalisations cross-linguistically.

Morphemes that have been shown to occur as nominalisers in non-embedded structures include dedicated nominalisers (e.g., Dolakha Newar, Genetti 2007), other general markers of dependency (e.g., Hup, Epps 2008), articles and number markers (e.g., Athpare, Ebert 1997) and, in a few cases, deictic elements such as demonstratives. ${ }^{5}$ Non-embedded nominalisations as described in the literature vary as to the source and number of their nominalising morphemes, and the ways these relate to other systems in the language. Three types can be discerned: (i) a single nominaliser, that is not itself part of a larger set, is used to form NENs; (ii) a single nominaliser drawn from a larger paradigm of items, such as demonstratives, is used to form NENs; and (iii) multiple nominalisers drawn from different parts of the language's grammar are used to form NENs. Each of these types is illustrated below.

The language Manange (Tibeto-Burman) has a single nominaliser, $-p \Lambda$ and thus a single way of forming non-embedded nominalisations (Hildebrandt 2004, Genetti et al. 2008). An example is shown in (4).

Manange

(4) $Y a^{52} k \wedge t t i^{55} m o-p \Lambda^{22} \quad k o$.

yak many COP-NMLZ EVID

'There were many yaks.' (Hildebrandt 2004: 83) 
In some cases a nominalising morpheme is drawn from a larger paradigm that is not fully exploited in non-embedded nominalisation. Usan (Madang, Trans New Guinea), for example, uses a speaker-proximal demonstrative form, $e$ 'this', in NENs (5). The Usan demonstrative paradigm also includes speaker-distal forms that distinguish three grades of elevation (ite 'up.there', umo 'down.there' and ire 'across.there'). However, these terms cannot be used to form NENs (Reesink 1987). Usan

(5) Ye ar ende asi igor-ibam $e$.

I idle thus look.for stay-1sG:FUT NMLZ

'I will just be looking around like that.' (Reesink 1994: 103)

A similar restriction is found in Malagasy. Out of more than a dozen demonstratives in the language (see Rasoloson and Rubino 2005:471 for the full paradigm), only izany can be used as an "exclamative determiner" (Potsdam 2011) forming a NEN, such as that in (6).

Malagasy

(6) Izany nisotro toaka tamin' ny fety! NMLZ drink booze at the party

'The people drinking at the party!' (Potsdam pers. comm.)

Contrastive NENs are attested in several languages. The nominalisers used in such cases are rarely paradigmatically contrastive elsewhere in the grammar. In Literary Burmese, for example, the form thii (7) functions as a nominaliser in complex clauses (e.g., in relativisation), a demonstrative, and a nominative case marker, as well as a nominaliser in NENs (Simpson 2008). The nominaliser mii (8) contrasts with thii on clausal nominalisations, indicating irrealis mood, but does not have comparable NP-level functions.

Literary Burmese

(7) U-Win-Win manee-ga yauq-laa thii.

U-Win-Win yesterday-PsT arrive-come NMLZ

'U Win Win arrived yesterday' (Simpson 2008:273)

(8) Neqhpan pyan laa mii. tomorrow return come NMLZ

'He will come back tomorrow.' (Simpson 2008:278)

Japanese has a set of multi-functional nominalisers that are used in non-embedded nominalisations. The nominaliser no in (9) is also the genitive case marker, while wake and mono in (10) and (11) are lexical nouns meaning 'reason' and 
'thing', respectively. The pragmatic meanings associated with the different nominalisers are described in the following section.

Japanese

(9) Sonna fukanoo na koto iwa-nai no.

such impossible COP thing say-NEG NMLZ

'Don't say such an impossible thing.' (Cook 1990:432)

(10) Asoko-ni ikoo tte itta wake.

that.place-to go:INT QUOT said NMLZ

'I said why not go there, you know.' (Horie 2008: 177)

(11) Sira-nai mono.

knOw-NEG NMLZ

'I don't know.' (Horie 2008: 176)

Table 1 summarises the nominaliser-to-paradigm relationship found in existing descriptions of non-embedded nominalisations. Where there is only a single nominalising morpheme used to form NENs, we find that the nominaliser is often drawn from a larger paradigm of items (e.g., Usan, Malagasy), but is not always (e.g., Manange). Contrastive nominalisers in NENs are typically drawn from different areas of the grammar (e.g., Literary Burmese, Japanese). What we do not find in existing descriptions is a contrastive set of nominalisers from a single paradigm that, when used in NENs, echoes the range of contrasts available in the source paradigm. In $\$ 3$ we fill this gap, showing that in several Timor-Alor-Pantar languages whole paradigms of demonstratives are used alternately to create NENs with different spatial, temporal, and pragmatic meanings.

Table 1. Classification of morphemes used in NENs

\begin{tabular}{lll}
\hline & Single NMLZ & Multiple NMLzs \\
\hline Not part of paradigm & Manange & Literary Burmese, Japanese \\
Part of paradigm & Usan, Malagasy & \\
\hline
\end{tabular}

\subsection{Meanings and pragmatic functions}

We describe non-embedded nominalisation in Timor-Alor-Pantar languages within the context of an easily-recognisable, but under-explored, form-function pairing. The TAP data support a broad understanding of NENs as pragmatically marked expressions that draw on two basic structural elements: the use of a typically embedded structure as a complete utterance, and the verbal presentation of an event or situation as an entity. Cross-linguistically, such constructions are 
associated with: (i) stance-taking attitudinal constructions (e.g., expressive, factive, emphatic, assertive, exclamative, counter-expectational, see example (12)), and; (ii) attention-directing functions (13). The expression of a particular stance through a non-embedded nominalisation directs an addressee to attend to the described situation in a particular way. These mutually re-enforcing themes are consistent with functions associated with insubordinate constructions as identified by Evans (2007), and with Yap et al.s (2011:8) claim concerning cross-linguistically common reinterpretations of nominalisers as stance markers (see also Yap et al. 2004).

Non-embedded nominalisations reify events and present them as independent facts, "endowed with a reality" (Matisoff 1972:246). They are associated with emphatic features such as vividness and exclamatory force ${ }^{6}$ (Woodbury 1985, Epps 2008), constativity, counter-expectation or frustration (Noonan 1997), verifiability and relevance (San Roque 2008), and/or focus (Bickel 1999, Genetti 2007). For example, in Belhare (Kiranti), one function of non-embedded nominalisation is to mark controversial positions where a speaker rejects a proposition presupposed by an interlocutor, and substitutes a counter-claim (Bickel 1999), as in (12). The Hup sentence in (13) is taken from a story where a deer teases a blinded jaguar to pounce on him, and illustrates the pointed, dramatic and consequently attentiondirecting qualities of a NEN structure in that language (Epps 2009).

Belhare
A: Endua khar-yu?
when go-NPST
'When does she go?'
B: Asen-ba tai-ya-ha, y-khat-ket-ni-ha.

yesterday-LOC come-INTR.PRF-PRF 3NS-go-ICP-NEG-NMLZ

'She has come yesterday, she is not going already now!' (Bickel 1999:10)

Hup

(13) Nut-áh rãh g'ét-ep, yãrám!

here-FOC 1sG stand-NMLZ jaguar

'Here I am, Jaguar!' (Epps 2009:306)

As mentioned in $\$ 2.2$, Japanese non-embedded nominalisations carry a distinct pragmatic force depending on the nominaliser used. For example, a NEN formed with no as in (9) conveys a strong degree of assertion (Yap et al. 2004), and can be interpreted as a command (Cook 1990, Horie 2011). By contrast, wake in (10) is used to offer an explanation or reason. The nominaliser mono in (11) indicates that the speaker is presenting the information as part of their personal experience (Horie 2008). 
In sum, common themes of non-embedded nominalisations are their stanceexpressing and attention-directing functions. They are used to pointedly present an event or situation, and an important element of this function is the event's identifiablity (cf. Enfield 2009:29). The addressee should be able to "locate" the proposition that is encoded as a nominalised clause, for example, as something they can immediately observe or act on, something they already know about (but may not be attending to sufficiently), or as something that complements or directly contrasts with previously held ideas concerning the event in question (e.g., in the case of counter-assertions and counter-expectationals). Non-embedded nominalisations in TAP languages further illustrate the way that these structures draw on features of identifiability and accessibility that are central to demonstrative use.

In addition to or even instead of pragmatic functions, in certain languages a nominalising morpheme on a main verb signals typical verb-domain information such as aspect (e.g., Mebengokre, Salanova 2006; Limbu, Bickel 1999), tense (Manange, Hildebrandt 2004), realis/irealis mood (e.g., Literary Burmese, Simpson 2008) or subject number (Hup, Epps 2008,2009 ). ${ }^{7}$ We will see in $\$ 3$ that temporal meanings are also an important component of some TAP nominalisations.

\section{Non-embedded nominalisations in TAP languages}

The Papuan languages of the TAP family are spoken on the islands of Timor, Alor and Pantar at the eastern end of the minor Sundic Island chain, just north-west of the Australian continent (see Map 1). The family consists of two primary subgroups, the Timor subgroup and Alor-Pantar subgroup. We discuss one language from the Timor subgroup, Bunaq, and two languages from the Alor-Pantar subgroup, Abui and Adang.

TAP languages typically have rich sets of distinctions in deictic categories. Most of the languages have multi-term demonstrative systems displaying four or more distinctions (e.g., Blagar, Steinhauer 1990; Abui, Kratochvíl 2007; Bunaq, Schapper 2010). Several systems encode three or more levels of elevation (e.g., Adang, Haan 2001; Klon, Baird 2008), and / or include other features such as visibility and knowledge (e.g., Teiwa, Klamer 2010; Western Pantar, Holton 2007).

In this paper, we discuss Bunaq, Adang and Abui demonstratives as used in non-embedded nominalisations. ${ }^{8}$ We focus on the meaning of demonstratives in relation to two features:

i. "accessibility" refers to the kinds of access that speech participants have to the objects they talk about (Hanks 2009: 12). An object with high accessibility may 


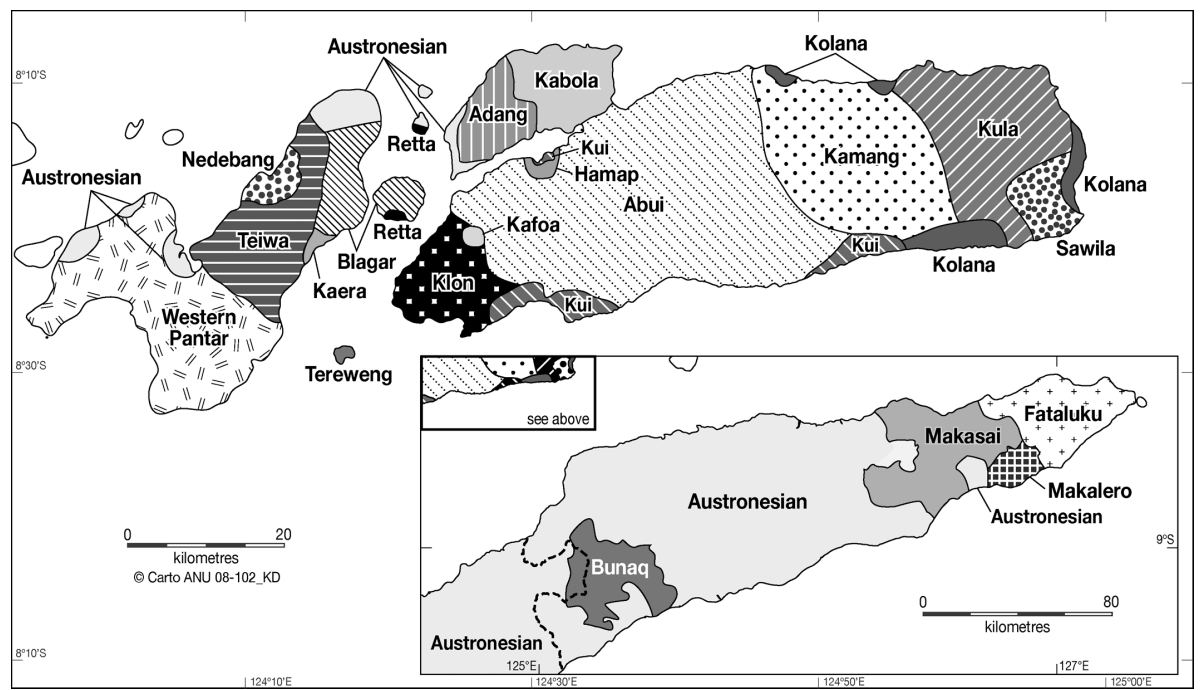

Map 1. Non-Austronesian languages of Timor, Alor, and Pantar (TAP)

be physically available to the hearer, for instance, by being reachable or visible, and/or pragmatically available by virtue of being topical or having the current attention of the hearer (Burenhult 2003). An object with low accessibility lacks these properties.

ii. "anchoring" refers to whether a speech participant, either the speaker or the addressee, acts as a reference point by which the hearer can identify a referent (so-called "person oriented" systems, see Diessel 1999a:50, Anderson and Keenan 1985:284).

We use the glosses 'THIs' and 'THAT' for demonstratives that indicate high and low accessibility, respectively, relative to a speech participant. The speech participant to which a demonstrative is anchored is indicated by the labels 'SPKR', for accessibility relative to the speaker, and 'ADDR', for accessibility relative to the addressee. For example, a demonstrative that indicates low accessibility relative to the speaker is glossed 'THAT.SPKR', while a demonstrative that indicates high accessibility relative to the addressee is glossed 'THIS.ADDR'.

Table 2 shows the demonstrative systems of Bunaq, Adang and Abui with respect to these features. As can be seen in the table, Bunaq has two speaker-anchored demonstratives that contrast in accessibility. The Adang set also includes two demonstratives, but these both encode high accessibility, and contrast with respect to participant anchoring. The Abui demonstratives include the "full" set, encoding all values with respect to participant anchoring and accessibility.

In addition to the speech participant-anchored demonstratives represented in Table 2, Bunaq and Adang have demonstratives that are not anchored to one 
Table 2. Accessibility and anchoring of demonstratives in the TAP languages under study $\dagger$

\begin{tabular}{lllll}
\hline Accessibility & Anchor & Bunaq & Adang & Abui \\
\hline THIS & SPKR & $\mathrm{X}$ & $\mathrm{X}$ & $\mathrm{X}$ \\
THAT & SPKR & $\mathrm{X}$ & & $\mathrm{X}$ \\
THIS & ADDR & & $\mathrm{X}$ & $\mathrm{X}$ \\
THAT & ADDR & & & $\mathrm{X}$ \\
\hline
\end{tabular}

$\dagger$ In the table "X" represents that the language has a demonstrative with the appropriate anchoring and accessibility.

speech participant. Bunaq has a specifier demonstrative that encodes uniqueness without anchoring to a speech participant (see \$3.2), while Adang has three demonstratives encoding levels of elevation relative to the speech situation as a whole (see \$3.3). These are discussed as relevant in the language-specific sections, and are glossed with 'THE' appended with further material to cover additional semantic dimensions.

Following a brief overview of nominalisation in the TAP languages (\$3.1), we examine the semantics of demonstratives in non-embedded nominalisations in Bunaq (\$3.2), Adang (\$3.3) and Abui (\$3.4). Each of these languages has a different demonstrative system arrangement, and these in turn have distinct spatial, temporal and epistemic applications in NENs, summarised in \$3.5. Throughout these sections, we use the brackets ' \{\} ' in free translations to approximate the pragmatic meaning expressed by the demonstrative forming a NEN.

\subsection{Structure and functions of TAP nominalisation}

Table 3 presents an overview of the syntax of demonstratives in the (pro-/ad-) nominal domain and as clausal nominalisers in TAP languages. Each type is exemplified, for Bunaq, in examples (14)-(17).

Table 3. Overview of syntactic functions of demonstratives

\begin{tabular}{|c|c|c|c|c|}
\hline \multicolumn{2}{|c|}{ Domain } & \multicolumn{2}{|l|}{ SyNTACTIC SCHEMA } & \multirow{2}{*}{$\begin{array}{l}\text { EXAMPLE } \\
(14)\end{array}$} \\
\hline Nomina & & {$\left[\ldots \mathrm{DEM}_{\mathrm{NP}}\right.$} & $\begin{array}{l}\text { referring expression, } \\
\text { pro- or ad-nominal }\end{array}$ & \\
\hline \multirow[t]{3}{*}{ Clausal } & Dependent & {$\left[_{\text {Clause }}\left[{ }_{\text {Clause }} \ldots D_{\text {Dem }}\right]_{\mathrm{NP}} \ldots\right]$} & $\begin{array}{l}\text { embedded nominalised } \\
\text { clause }\end{array}$ & (15) \\
\hline & & {$\left[{ }_{\text {ClaUse }} \ldots D_{\text {Dem }}\right]_{\text {NP }}\left[{ }_{\text {CLAUSe }} \cdots\right]$} & $\begin{array}{l}\text { nominalised thematic } \\
\text { clause }\end{array}$ & $(16)$ \\
\hline & Independent & {$\left[{ }_{\text {CLAUSE }} \cdots D \text { DEM }\right]_{\mathrm{NP}}$} & $\begin{array}{l}\text { non-embedded nomi- } \\
\text { nalised clause }\end{array}$ & (17) \\
\hline
\end{tabular}


The expected use of demonstratives is as part of a referring expression, ${ }^{9}$ for instance, in NPs such as that in (14) referring to a mango. In addition, demonstratives are used to nominalise clauses in three different contexts. First, there are embedded nominalised clauses in which the demonstrative nominalises a clause functioning as the argument of a predicate (15). Note that the absence of the nominalising demonstrative would make (15) ungrammatical. Second, a thematic nominalisation is a clause that is dependent on a following conjoined clause; it denotes a topical setting in terms of which the event in the conjoined clause is to be understood (16). Similar thematic constructions using demonstratives are found widely in Papuan languages (de Vries 1995, 2006; Haiman 1978). The third use of demonstratives as nominalisers is in independent non-embedded nominalisations (17).

Entity-referring expression

(14) Markus $\left[\begin{array}{ll}z o & \text { bara }\end{array}\right]_{\mathrm{NP}}$ sura.

Markus mango THAT.SPKR ask

'Markus asked about that mango.'

Embedded clause

(15) Markus [teo gene neto cier bara $]_{\text {CLAUSE }}$ sura. Markus where at 1SG sleep THAT.SPKR ask

'Markus asked about where I slept.'

Thematic nominalisation

(16) $[\text { Neto cier baza }]_{\text {CLAUSE }}$, Markus mar mal. 1SG sleep THAT.SPKR Markus garden go 'When I slept, Markus went to the garden.'

Non-embedded nominalisation

(17)

$$
\begin{aligned}
& {[\text { Neto cier bara }]_{\text {CLAUSE }}} \\
& 1 \text { sG sleep THAT.SPKR } \\
& \text { 'I was sleeping \{dammit\}!' }
\end{aligned}
$$

The structure of TAP clausal nominalisations using demonstratives is represented in (18). The demonstrative is the head and takes the whole clause as its complement. There is no change to the structure of the clause, such as in the coding of arguments (e.g., subjects becoming possessors) or the tense, aspect or mood of the verb. 
(18)

a. [[clause complement] demonstrative]

b.

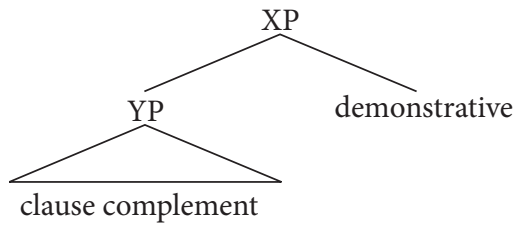

Structurally, there is no difference between dependent and independent clause nominalisations. It might be suggested that a clause final demonstrative in a nonembedded clause is an adverbial or verbal modifier. This analysis cannot be sustained for demonstratives with scope over clauses in the TAP languages. In Bunaq, for instance, a verbal modifier analysis is excluded for the following reasons. Post-verbal modifiers can be ordered differently relative to one another to obtain different scopal readings, as shown in (19a)-(19b) (see Schapper 2010:481-482). By contrast, a clausal demonstrative only occurs in clause-final position (19c), and cannot precede a post-verbal modifier (19d).
a. Neto sare teni gie.
1sG ascend again PROSP
'I intend to ascend again'.
1 sG ascend PROSP again
'I again intend to ascend.'
b. Neto sare gie teni.
c. Neto sare teni gie bare.
1SG ascend again PROSP THIS.SPKR
'I again intend to ascend \{see here\}!'
d. ${ }^{*}$ Neto sare teni bare gie.
1 sG ascend again THIS.SPKR PROSP

Similarly, in Adang, aspectual clitics normally attach to the final element in the clause, including post-verbal adverbs. By contrast, aspectual clitics attach not to the clausal demonstrative but to the preceding element. Such syntactic restrictions show that clausal demonstratives in the TAP NENs are not adverbial, but head a phrase in which a complete clause is the complement.

Whilst the structure of dependent and independent nominalisations is the same, the pragmatic availability of demonstratives differs among constructions. The overwhelming majority of dependent nominalisations use the definitenessmarking, topic-tracking demonstratives, namely Bunaq bara, Adang ho and Abui do. However, in NENs all members of the demonstrative paradigm appear to be equally available. The meanings associated with different demonstrative choices to form NENs are illustrated in the following sections. 


\subsection{Bunaq}

Bunaq (described in Schapper 2010) has a three-way system of spatial demonstratives (Table 4). ${ }^{10}$ The system contrasts a demonstrative denoting speaker-anchored high accessibility, bare THIS.SPKR, versus a demonstrative denoting speaker-anchored low accessibility, bara THAT.SPKR. The third demonstrative in the paradigm, doe THE.ONE, is not anchored to a speech-participant; it functions to zero in on and exclusively pick out a salient referent in the immediate situation, roughly equivalent to the English the one in particular.

Table 4. Bunaq situational demonstratives

\begin{tabular}{llll}
\hline INANIMATE form & ANIMATE form $\dagger$ & Gloss & $\begin{array}{l}\text { Referential characteristics in } \\
\text { exophoric use }\end{array}$ \\
\hline bare & bari & THIS.SPKR & high speaker accessibility \\
bara & bari & THAT.SPKR & $\begin{array}{l}\text { low speaker accessibility } \\
\text { doe }\end{array}$ \\
doi & THE.ONE & $\begin{array}{l}\text { identified as being precisely } \\
\text { the entity which is at issue }\end{array}$ \\
\hline
\end{tabular}

$\dagger$ The choice of demonstrative form depends on the noun class of the NP head. The ANIMATE form of the demonstrative is used where the head of the NP belongs to the ANIMATE noun class. In all other cases, including the clause nominalisations discussed here, which have no nominal head, the INANIMATE form is used. The ANIMATE forms will not be discussed further here.

Bunaq demonstratives can be used adnominally and pronominally. Adnominally, they follow the noun. In (20) bare indicates that the speaker has direct access to the mango, such as if the speaker were holding, reaching to or looking at the mango. In (21) bara points to the speaker's lack of access to the mango, in this case, by virtue of its being in the possession of Markus. In (22) doe specifies that there is one entity in particular that the speaker picks out as the referent.

(20) Neto zo bare a.

1sG mango THIS.SPKR eat

'I am eating this mango.'

(21) Markus ba?a a.

Markus THAT.SPKR eat

'Markus is eating that (mango).'

(22) Neto o Markus doe a.

1SG and Markus THE.ONE eat

'Markus and I are eating this/that particular (one).'

In Bunaq, NENs are exclamatory clauses in which the speaker asserts a stance concerning the proposition conveyed by the clause. The demonstratives used in NENs 
carry temporal and knowledge-related meanings (in relation to the speaker's, and/ or to the addressee's knowledge) which are connected to their nominal uses.

Marking a NEN, bare THIS.SPKR indicates that the event is in the immediate experience of the speaker. For instance, in (23) the speaker uses bare to assert that the process of building the house is ongoing, being present and visible at the time of speaking. The NEN directs attention to the proposition and its current actuality, that is, the speaker (and, by extension, the addressee) can see, here and now, that the house is being built. Without the nominalising demonstrative, (23) would be a simple declarative 'he builds/built the house' with no suggestion of current visibility.

(23) Barina h-oron bare.

s/he FOC 3INAN-make THIS.SPKR

'He is building (the house) \{as can be seen\}.'

NENs with bare are also used to vivify past time events. Example (24) comes from a text in which children recount an encounter with a spirit to an adult. The adult hearer is sceptical about the story and suggests that it wasn't a muk gomo 'earth spirit' that they saw. One of the children reacts against this suggestion, saying that the sighted individual had her face covered in blood (a characteristic implied to be inconsistent with those of a normal person). She uses a bare-marked NEN to assert the event is true, by construing it as if it is an event that can be seen in the "here and now" and is thus evident.

(24) Muk g-omo on e! Barihasi g-ewen earth 3-master do TAG s/he thus 3-face ho ho on bare.

bloody REDUP do THIS.SPKR 'It (was) an earth spirit! Her face (was) all bloodied thus \{it's true\}.'

Bare is thus used to assert propositions which the speaker regards as apparent and verifiable either because they are in the speech situation or the speaker has prior direct evidence for them.

Bunaq bara THAT.SPKR is used in NENs to assertively refer to past time events. In (25) the use of the NEN marked with bara emphasises that the speaker did plant beans despite having broken her right hand. In the absence of the demonstrative, (23) would be a simple statement without any exclamative force.

D-on suel bare rele neto ho gapa gol uen hota bara! REFL-hand left THIS.SPKR with 1sG ko.bean small one plant THAT.SPKR 'I planted a few beans with this left hand of mine $\{$ I did $\}$ '. 
Example (25) presents information that is (assumed to be) new. Bara can also mark a proposition that is considered to be obvious, that is, is an established, uncontroversial fact from the speaker's perspective. In (26) the speaker responds to a question concerning his origin with a non-embedded nominalisation marked by bara, asserting that naturally he had come from the tops of the sago palms, as that was where he lived.

(26) Nei esen haqe gene hak wa ni bara.

1PL.EXCL above there at sago.palm top on THAT.SPKR

'We were up there on top of the sago palms \{of course\}.'

In NENs, doe THE.ONE marks clauses describing events that have occurred in the recent past. In (27) doe indicates that the death of Mau Paran had just occurred at the time of utterance. The use of a NEN here also draws attention to the speaker's exasperation at the recent loss of her husband.

(27) Tuen goet on oa Mau Paran heser hazal doe?

how like do Pfv Mau Paran dead finished THE.one

'What (should we) do now that Mau Paran has died \{just recently\}?!'

Doe is also used in referring to events that are not necessarily recent but of which knowledge is or should be available to both speaker and addressee. Example (28) is from a text in which two children cook the yams their parents had explicitly told them not to cook. The nominalising demonstrative doe marks that the smell of the cooking yams had recently reached the parents (the speakers in this example), and furthermore that it was obvious that it would, and the children must have known that it would happen. Example (29) describes an event, the discovery of fire, that occurred in the mythical past. Doe construes the clause as a happening of the recent past, because like a recent event its effects are still being felt today, and are well known to be the case.

$$
\text { Gie pie ola nei n-o pir doe! }
$$

3.POss steam below 1PL.EXCL 1EXCL-SRC reach THE.ONE

'Its steam reached us down below \{as we all knew it would\}.'

(29) Tas mil genereu hoto hati doe.

village inside in house fire exist THE.ONE

'There were henceforth fires in houses in the villages \{as we all know to be so\}.'

In sum, Bunaq situational demonstratives are used in NENs to emphasise the temporal or epistemic setting of an event. Bare THIS.SPKR and bara THAT.SPKR mark propositions that are part of a speaker's actual knowledge, but from different temporal perspectives. Bare marks that an event is present and visible, or that the speaker has direct evidence for the clausal proposition as if it were present 
and visible. Bara marks a clause as denoting a completed, past time event and/or a proposition whose truth the speaker sees as an incontrovertible, established fact as if it were a completed event. Doe THE.ONE indicates that the event occurred in recent past time, and that knowledge of the event is or should be available.

\subsection{Adang}

Adang (described in Haan 2001) has five spatial demonstratives (Table 5). The paradigm makes a primary distinction between reference to items that are immediately accessible to speech act participants (speaker and addressee) and those that are not. Entities in the immediate speech situation are identified either as speaker-anchored accessible, ho? THIS.SPKR, or addressee-anchored accessible, ho THIS.ADDR. Entities not in the immediate speech situation are identified according to their elevation relative to the speech participants. Entities referred to by an elevational demonstrative must be visible to the speaker (and assumed to be so for the addressee).

Table 5. Adang demonstratives

\begin{tabular}{lll}
\hline Form & Gloss & Referential characteristics in exophoric use \\
\hline hors & THIS.SPKR & high speaker accessibility \\
$h o$ & THIS.ADDR & high addressee accessibility \\
$h \varepsilon m s$ & THE.ACROSS & located level with speech situation \\
$h \varepsilon t s$ & THE.UP & located above speech situation \\
heps & THE.DOWN & located below speech situation \\
\hline
\end{tabular}

Adang demonstratives can be used both adnominally and pronominally. A demonstrative follows the noun it modifies. Example (30) illustrates the adnominal use of horo THIs.SPKR. Example (31) illustrates the pronominal use of ho THIS.ADDR and hemo THE.ACROss.

(30) Bel hors mud ra-de eham.

dog THIS.SPKR orange 3-eat INCH

'This dog (close to me) is about to eat an orange.'

(31) Ho/ hems mud la-de eham.

THIS.ADDR THE.ACROSS orange 3-eat INCH

'That (one) close to you / over there is about to eat an orange.'

Adang non-embedded nominalisations are exclamative clauses carrying spatial and knowledge-related meanings that depend upon the demonstrative used. A NEN formed with horo THIS.SPKR draws transparently on its adnominal or 
pronominal meaning, describing events that are occurring (or about to occur) in the immediate sphere of the speaker. Pragmatically, a NEN formed with horo is assertive, and often conveys the speaker's surprise that $\mathrm{s} /$ he had not noticed the event earlier, as it is something they should have been aware of. Thus, (32) can be interpreted as an exclamation in which the speaker asserts the proposition on the basis of his or her access to it, and potentially also an expression of surprise at having only just realised what is happening (John Haan pers. comm).

(32) Bel mud ra-de eham horo.

dog orange 3-eat INCH THIS.SPKR

'A dog is/was about to eat an orange \{it's true, and I hadn't noticed\}!'

Non-embedded nominalisations formed with ho THIS.ADDR describe events that are occurring in the immediate sphere of the addressee, and direct the addressee's attention towards that event. Paralleling the speaker-centred semantics of NENs formed with horo, in using ho the speaker further indicates that the addressee is or should be aware of the situation described in the clause. The NEN in (33), for example, could be exclaimed in the context of the speaker seeing Heri eating oranges which are intended for the addressee.

(33) Heri mud $2 a-d \varepsilon=e h \quad h o$ !

Heri orange 3 -eat=PROG THIS.ADDR

'Heri is eating an orange \{don't you see?\}!' (Haan 2001:205)

Demonstratives in Adang that do not denote high accessibility can also form non-embedded nominalisations. They locate the event as removed from the speech participants, but visible to them at the time of speaking. In (34), hets locates the deer's lying down as occurring at a higher elevation than the speech participants and within their sight.

Aru tar=am hets.

deer lie.down $=$ PFV THE.UP

'A deer has lain down up there \{we can see\}.' (Haan 2001:206)

The Adang demonstratives are thus used in NENs to express the physical and epistemic accessibility of an event either in relation to the speaker in the case of horo THIS.SPKR, or the addressee in the case of ho THIS.ADDR. The demonstrative is used to denote actual, existing access, and commonly conveys an added judgement concerning potential awareness: this is an activity that the speaker or addressee should know or see. Elevation marked demonstratives are used in NENs to describe events that are removed from, but visible to, both speech participants, and to locate the event in space relative to the speech event. 


\subsection{Abui}

Abui (described in Kratochvíl 2007, 2011) has a four-way contrast in its demonstrative system, differentiating high and low accessibility for both speaker and addressee. The forms are given in Table $6 .^{11}$

Table 6. Abui demonstratives

\begin{tabular}{lll}
\hline Form & Gloss & Referential characteristics in exophoric use \\
\hline$d o$ & THIS.SPKR & high speaker accessibility \\
$o$ & THAT.SPKR & low speaker accessibility \\
to & THIS.ADDR & high addressee accessibility \\
$y o$ & THAT.ADDR & low addressee accessibility \\
\hline
\end{tabular}

Abui demonstratives have pronominal and adnominal functions. Adnominally, they can either precede or follow the head of an NP (Kratochvíl 2007: 161-163). Preceding the $\mathrm{N}$, they refer to a referent in space, as in (35a) and (36a). Following the $\mathrm{N}$, they anaphorically refer to referents in discourse, as in (35b) and (36b). Abui demonstratives follow clauses they nominalise.
DEM N
a. do fala
THIS.SPKR house
'this house (near me)'
$\mathrm{N}$ DEM
b. fala do house THIS.SPKR
'this house (I just mentioned)'
a. yo fala
THAT.ADDR house
b. fala yo
'that house (distal from you)'
house THAT.ADDR
'that house (you mentioned a while ago)'

(36)

(Kratochvíl 2007: 161)

In non-embedded nominalisations, speaker-anchored demonstratives indicate the temporal location of an event as (near-)present or otherwise. Do THIS.SPKR is used for events that are ongoing in the present, just past, or just about to occur (37).

(37) Di de-melang da-wai yaar do.

3SG 3-village 3.PAT-turn go.CMPL THIS.SPKR

'He is about to / is going/ just went back to his village.'

(Kratochvíl 2011: 774)

Speaker-anchored demonstratives can also indicate the speaker's attitude towards an event. ${ }^{12}$ In NENs with $d o$, the speaker construes the event denoted by the clause as directly experienced by him/herself. This is seen in the emphatic expressions of pain and discomfort in (38) and (39). 
(38)

Do na-rik baai do!

THIS.SPKR 1SG.PAT-hurt as.well THIS.SPKR

'This hurts/hurt me! \{I really feel/felt it\}'

(Kratochvíl 2011: 778)

(39) Na nala nee=ti beekado.

1SG something eat=then bad THIS.SPKR

'I can't/couldn't swallow anything. \{I really feel/felt it\}'

(Kratochvíl 2011: 777)

In accordance with the demonstrative's semantics of lower accessibility, nonembedded nominalisations with $o$ THAT.SPKR can indicate a considerable temporal distance between the time of speaking and the time of the event referred to in the clause (40).

(40) Di de-melangda-wai yaar o.

3sG 3-village 3.PAT-turn go.CMPL THAT.SPKR

'He went back to his village some time ago.' (Kratochvíl nd.)

Nominalisations with $o$ THAT.SPKR may also detail events which the speaker asserts to be possible but not (yet) realised. Expressing an unrealised event in this way typically implies a positive disposition toward the event, and the construction may be used as an invitation to action. In (41) o suggests that the addressee is being encouraged to enter the house, while in (42) it presents the speaker's proposal as a promising activity for the day.

(41) Marang mit-i o! come.up.ICP sit-PFV THAT.SPKR

'You could come up [into my house] and sit down. \{Please come!\}'

(Kratochvíl 2011: 780)

(42) $\quad P i$

Afena Hapong pa te-bikeng-ra o!

1PL.INCL Afena Hapong go.down.IPFV DISTR-louse-AUX THAT.SPKR

'We could go to Afena Hapong and search for each other's lice. \{Let's go!\}'

(Kratochvíl 2011: 780)

Main clauses marked with $o$ THAT.SPKR (40-42) thus share the feature that they describe events that are removed from the speaker in the here-and-now, either through having happened some time ago, or because they have yet to occur.

The addressee-based Abui demonstratives are used in non-embedded nominalisations to "appeal to the addressee's knowledge of the event" (Kratochvíl 2011: 773). Paralleling (37)-(39), the clauses in (43) and (44) are nominalised with the higher access demonstrative, to THIS.ADDR, and pertain to present or near-present time events. The NEN carries the added implication that the addressee has enough 
current evidence available to verify the proposition for him/herself, and that the speaker thus believes him or her to be already aware of the state of affairs described.

(43) Di de-melang da-wai yaar to.

3SG 3-village 3.PAT-turn go.CMPL THIS.ADDR

'He just went back to his village \{as you know\}.'

(Kratochvíl 2011: 774)
$N i-y a$
ha-rik
to.
1PL.EXCL-mother 3.PAT-sick THIS.ADDR
'My mother is sick \{as you know\}.'
(Kratochvíl 2011: 777)

While examples such as (43) and (44) indicate the speaker's opinion that the addressee already has actual knowledge of a (near-)present event, NENs formed with yo THAT.ADDR are concerned with the addressee's potential knowledge concerning more removed events. In particular, yo is used to assert that the addressee really should know or understand the proposition, and that their apparent ignorance of it is surprising. For example, (45) would be suitable where the speaker has already told the addressee about the person's return to his village, and cannot understand why they need to explain it again. Example (46) refers to a potential event. Similar to (41), this utterance encourages the addressee (in this case, a child) to undertake a certain course of action, but as a command rather than an invitation.

(45) Di de-melangda-wai yaar yo.

3SG 3-village 3.PAT-turn go.CMPL THAT.ADDR

'He went back to his village some time ago \{as you should know\}.'

(Kratochvíl nd.)

(46) A-ran ba taa yo!

2sG.PAT-quiet and lie THAT.ADDR

'You calm down and sleep \{you know you should\}!' (Kratochvíl 2011: 780)

In sum, Abui demonstratives are used in NENs to express the temporal and epistemic accessibility and non-accessibility of an event. Accessible demonstratives (do THIS.SPKR, to THIS.ADDR) are used by the speaker to construe an event as occurring in a (near-)present time, and as being part of the speaker or addressee's direct experience. Demonstratives denoting lower accessibility ( $o$ THAT.SPKR, yo THAT.ADDR) are used in expressing past or potential events that the speaker or addressee could or should attend to. 


\subsection{Summary and discussion of TAP NENs}

The TAP languages Bunaq, Adang and Abui each use demonstratives to form parallel non-embedded nominalisations. The meanings associated with the demonstratives, according to speech-participant anchoring and accessibility specifications, are summarised in Table 7. Generally, high accessibility THIs forms are associated with (near)-present time and actual experience, and low accessibility THAT forms are associated with non-present time and potential experience. However, specific meanings are not completely consistent across the languages, as each demonstrative is part of a larger paradigmatic system, and is accordingly constrained differently by the other terms within the system. In this section we discuss the TAP NEN demonstrative meanings and outline how certain semantic associations are shared with demonstrative constructions in other, unrelated languages.

Table 7. Comparison of demonstrative meaning in TAP NENs

\begin{tabular}{|c|c|c|c|c|c|}
\hline & & Bunaq & Adang & Abui & Meanings \\
\hline \multirow[t]{2}{*}{ Speaker } & THIS.SPKR & bare & horo & do & $\begin{array}{l}\text { (near-)present time; speaker-knowledge } \\
\text { with emphasis on personal experience }\end{array}$ \\
\hline & THAT.SPKR & bara & & $o$ & $\begin{array}{l}\text { non-present time, including past actual } \\
\text { or future possible events }\end{array}$ \\
\hline \multirow[t]{2}{*}{ Addressee } & THIS.ADDR & & ho & to & $\begin{array}{l}\text { (near)-present time; addressee knowl- } \\
\text { edge }\end{array}$ \\
\hline & THAT.ADDR & & & yo & $\begin{array}{l}\text { non-present time; potential addressee } \\
\text { knowledge }\end{array}$ \\
\hline
\end{tabular}

Common to the three languages is the presence of a speaker-anchored, accessible marked (THIS.SPKR) demonstrative. In each case, main clauses marked by this demonstrative are associated with the vivid presentation of (near-)present time events, and the personal experience of the speaker. Speaker-anchored non-accessible (THAT.SPKR) demonstratives are associated with non-present time. Bunaq uses its THAT.SPKR form to mark an event as having definitely occurred, whereas in Abui THAT.SPKR marks both past and potential events.

The temporal contrast implied by the high and low accessibility demonstratives in Bunaq and Abui is mirrored in languages such as Panare (Cariban, Gildea 1993) and Kilba (Chadic, Schuh 1983 as discussed by Diessel 1999b), where speaker-anchored proximal and distal demonstratives provide the source for contrastive present and non-present copulas or tense auxiliaries. ${ }^{13}$ Gildea (1993) argues that in Panare, the speaker proximal demonstrative has developed into a present/ near future tense auxiliary, whereas the erstwhile distal demonstrative can specify both past and distant future time, showing similarities quite close to the semantic situation 
in Abui. Such systems presumably reflect the experiential conflation of spatial and temporal distance (see also Fleck 2003, Faller 2004) as well as relating to the arguably universal tendency to draw time descriptors from space-oriented domains (see, e.g., Traugott 1975, Haspelmath 1997, Diessel 1999b, Casasanto and Boroditsky 2008).

Addressee-anchored demonstrative forms, found in Adang and Abui only, are associated with addressee knowledge. ${ }^{14}$ Adang has a single demonstrative denoting addressee accessibility (THIS.ADDR), used in NENs to suggest that the addressee should be aware of the described event. Abui makes a contrast between actual (THIS.ADDR) and potential (THAT.ADDR) addressee knowledge. As for the speakeranchored forms, NENs formed with high accessibility demonstratives focus on the actual experience of the addressee. More generally, the association of high accessibility demonstrative forms with NENs that express personal experience (which can be seen as a kind of direct evidence, see, e.g., Mithun 1999, Loughnane 2009) adds to observations concerning synchronic and diachronic links between demonstratives and evidential markers (see Aikhenvald 2004, Blass 1989, de Haan 2008, Pitkin 1984).

In addition, Bunaq and Adang have demonstratives that fall outside of the speech-participant anchored and access-specified demonstrative model presented above. Bunaq doe 'the one' is not anchored to a speech participant in its exophoric use and is used to pick the single object(s) that are at issue in the discourse. As an epistemic and temporal specifier, doe indicates the event both belongs to recent past time, and represents knowledge that is shared. The pairing of these two features in multifunctional deictic forms is also reported for Lai Chin (Barnes 1998) and Duna (San Roque 2008), perhaps reflecting a higher likelihood for recent events (e.g., as opposed to distant past or future events) to be clearly identifiable as common knowledge.

In Adang elevational demonstratives, the presence of a geographical feature in the meaning appears to "block" anything other than a spatial interpretation in non-embedded nominalisations, in accordance with argumentation by Burenhult (2008) concerning spatial meanings in demonstratives more generally. The Adang demonstratives also have a built-in evidentiality feature, however, insofar as they are only used in reference to visible events.

\section{Conclusion}

The TAP non-embedded nominalisations combine several elements that are widely used cross-linguistically as stance-expressing and attention-directing strategies: the use of a typically embedded structure as a complete utterance, the verbal presentation of an event or situation as an entity, and the exploitation of the semantics 
of identifiability and engagement encoded by certain demonstratives. The data from Bunaq, Adang and Abui make an addition to the typology of NENs, and contribute to our understanding of demonstrative functions and meanings.

In the three TAP languages under discussion, non-embedded nominalisations use demonstrative morphemes from a single paradigmatic system to create contrastive attention-directing constructions. As described in $\$ 2.2$, this contrasts with hitherto described NEN constructions, which typically involve either a single nominalising morpheme, or several unrelated nominalising forms drawn from different sources in the grammar. How paradigms of demonstratives involved in systematic NEN formation develop and change over time (e.g., into mood or evidentiality markers) remains to be investigated.

Traditionally, demonstrative meaning has been treated in terms of concrete spatial parameters, and in grades of distance from a deictic centre in particular (e.g., Anderson and Keenan 1985, Fillmore 1997, Diessel 1999a). More recently, treatments of demonstratives have focused on constellations of semantic, epistemic and discourse-pragmatic properties of distinctions. Beginning with studies such as Kirsner (1979) and Himmelmann (1997:43-89), there have been significant challenges to the idea that space is always fundamental to demonstrative meaning, and in particular the premise that physical distance is crucial to their use. Recent studies have emphasised that perception, attention, prior knowledge and the ongoing interaction itself, rather than simply individuals within it, are all simultaneous features of context that influence demonstrative choice (e.g., Enfield 2003; Hanks 1990, 1992, 2005, 2009; Diessel 2006; Özyürek 1998; Burenhult 2003; Küntay and Özyürek 2006; Piwek et al. 2008). Under this approach, demonstratives are argued to position referents by a complex interaction of knowledge, attention and other contextual features of the speech situation. This accords well with the functions of demonstratives in NENs.

Standard characterisations of demonstratives see them as dealing with a world of objects, locating and identifying referents in the speech situation or discourse. This study illustrates one way that demonstratives can also be used with scope over clauses, an example of demonstrative elements "shifting into the predicate" (Haig 2011), and being used to encode engagement, the "mental directedness of speech act participants towards a state of affairs" (Landaburu 2007, Evans 2010).

The demonstratives as applied to events and propositions in NENs illustrate the interweaving of spatial, temporal and epistemic accessibility in lived and talked about experience. Literal spatial meanings take a minor role, except where a geographic feature is part of the demonstrative. High accessibility 'THIs' forms are associated with present or near-present time and actual individual experience. Low accessibility 'THAT' forms are associated with non-present time and potential knowledge. Far from being limited to pointing out concrete objects, where 
the appropriate syntactic capacity exists, demonstratives express spatial, temporal, and epistemic features in relation to events and states.

\section{Notes}

* This paper was first presented at SEALS XX, Zürich, 2010. Many thanks to Nikolaus Himmelmann for insightful remarks on this occasion. Thanks also to Ger Reesink and Marian Klamer for commenting on an earlier version of the paper. Schapper's field research was supported by the project grant "Alor-Pantar languages: Origins theoretical impacts" 08-EuroBABEL-OP-O25 from De Nederlandse Organisatie voor Wetenschappelijk Onderzoek.

1. "Local deictic elements which can be used pronominally [...] or adnominally [...] are commonly called demonstratives" (translation Schapper). Himmelmann (1997) excludes deictics such as English 'here' and 'there' from the category of demonstratives on syntactic grounds. Other authors (e.g., Diessel 1999a, 1999b) treat these as "locative" demonstratives, relevant at the level of the clause. Such items are not diagnostic of NPs and do not have nominalising functions. As such we follow Himmelmann (1997) and do not include them in our discussion.

2. We do not use the term "epistemic" in the restricted sense of "epistemic modality" (i.e., concerning judgments of factual status), but as a more general term concerning knowledge-related features (e.g., information source, surprise, certainty).

3. The issue of whether all such clauses are genuinely noun phrase structures remains a point of inquiry for investigation on a language-by-language basis (Genetti 2011, Simpson 2008). In this paper we restrict ourselves to relatively straightforward synchronic cases of NENs.

4. We gloss all nominalising morphemes in the examples in $\$ 2$ as NMLZ 'nominaliser'. Other interlinear glosses in $\$ 2$ are those provided by the cited authors, with minimal changes to conform to abbreviations recommended in the Leipzig Glossing Rules. Abbreviations used in this paper that are not included in the LGR are: ANT 'anterior'; CMPL 'completive aspect'; EVID 'evidential'; FACT 'fact'; ICP 'inceptive'; INAN 'inanimate'; INCH 'inchoative'; INT 'interrogative'; PAT 'patientive’; SRC 'source'. See also $\$ 3$ for conventions used to gloss demonstratives in Bunaq, Adang, and Abui. In TAP language examples, text in free translations bracketed with \{\} approximates the pragmatic meaning expressed by the demonstrative forming the NEN.

5. It is of course also cross-linguistically common for nominalisers to develop from demonstratives or other determiners (see Diessel 1999a).

6. Under definitions of "exclamative" constructions that incorporate scalarity (e.g., Michaelis 2001), only certain NENs are exclamative sentences.

7. The strengthening of such meanings can support reanalysis of the nominalizer as an "ordinary" verbal inflection; see, e.g., Simpson (2008).

8. The data used in this paper are from the following sources: Bunaq, Schapper (2010) and Schapper (fieldnotes); Adang, Haan (2001); Abui, Kratochvíl (2007, 2011, nd). Analyses for Adang come from Schapper in pers. comm. with Haan. The syntactic analysis of the Abui 
demonstrative system is different to that presented in Kratochvíl $(2011,2007)$ and comes from Schapper fieldnotes. See also footnote 11.

9. Note that we also take "discourse deixis" (Diessel 1999a:36) to be included under the label "referring expression". In discourse deixis, a demonstrative is used to point back or forth to propositions in the discourse (e.g., a previously described situation). Such demonstrative uses are referential but in relation to propositions rather than entities.

10. This table presents only the Bunaq situational demonstratives, i.e., those that can be used in contexts of situation deixis with accompanying gestural pointing. Bunaq has two further demonstratives belonging to the demonstrative paradigm; they have no situational use and will not be discussed here. See Schapper (2010) for the morpho-syntactic properties defining the class of demonstratives and their pragmatic functions.

11. Kratochvíl $(2007,2011)$ includes several other items in the set of demonstratives. These are the elevation-marked terms oro 'ACROss', $o$ 'LOW.MID', ó 'HIGH.MID', wò 'DOWN.DIST', and wó 'HIGH.DIST', and the specifiers $h u$ and $n u$. These two sets have different syntactic distributions from one another and from the set of demonstratives we identify. We analyse them as constituting distinct word classes, the former as locationals (as defined in Schapper 2010:283-308) and the latter as articles, and do not discuss them in this paper.

12. Kratochvíl (2011: 775-780) treats demonstratives in NENs as having two distinct functions at the sentence level: (i) mapping evidentiality, and (ii) marking assertions. We do not attempt to separate the various aspects of demonstrative meaning from one another but rather see them as simultaneous features arising from the speech event.

13. We do not claim that these constructions are non-embedded nominalisations, but mention them because of parallels to the temporal meanings found in the TAP instances.

14. Addressee knowledge in Bunaq is encoded by the addressee locational $o$. Whilst this is deictic, it has distinct morpho-syntax, cannot be used to nominalise clauses, and is not part of the demonstrative paradigm (Schapper 2010:95-98).

\section{References}

Aikhenvald, Alexandra Y. 2004. Evidentiality. Oxford: Oxford University Press.

Anderson, Stephen R., and Edward Keenan. 1985. Deixis. In Timothy Shopen (ed.), Language typology and syntactic description, Volume 3: Grammatical categories and the lexicon, 1st edn., 259-308. Cambridge: Cambridge University Press.

Baird, Louise. 2008. A grammar of Klon. Canberra: Pacific Linguistics.

Barnes, Jonathon. 1998. Tsuu khaa tii hla?: Deixis, demonstratives and discourse particles in Lai Chin. Linguistics of the Tibeto-Burman Area 21(1). 53-86.

Bickel, Balthasar. 1999. Nominalisation and focus in some Kiranti languages. In Yogendra P. Yadava and Warren W. Glover (eds.), Topics in Nepalese linguistics, 271-296. Kamaladi, Kathmandu: Royal Nepal Academy.

Blass, Regina. 1989. Grammaticalisation of interpretive use: The case of $r \varepsilon$ in Sissala. Lingua 79. 299-326. 
Burenhult, Niclas. 2003. Attention, accessibility, and the addressee: The case of the Jahai demonstrative ton. Pragmatics 13(3). 363-379.

Burenhult, Niclas. 2008. Spatial coordinate systems in demonstrative meaning. Linguistic Typology, 12(1). 99-142.

Casasanto, Daniel and Lera Boroditsky. 2008. Time in the mind: Using space to think about time. Cognition 106. 579-573.

Comrie, Bernard and Sandra A. Thompson. 2007. Lexical nominalization. In Timothy Shopen (ed.), Language typology and syntactic description, Volume 3: Grammatical categories and the lexicon, 2nd edn., 334-381. Cambridge: Cambridge University Press.

Cook, Haruko Minegishi. 1990. An indexical account of the Japanese sentence-final particle no. Discourse Processes 13. 401-439.

DeLancey, Scott. 2011. Finite structures from clausal nominalisation in Tibeto-Burman. In Foong Ha Yap, Karen Grunow-Hårsta and Janick Wrona (eds.), Nominalization in Asian languages: Diachronic and typological perspectives, 343-359. Amsterdam/Philadelphia: John Benjamins.

Diessel, Holger. 1999a. Demonstratives: Form, function, and grammaticalisation. Amsterdam/ Philadelphia: John Benjamins.

Diessel, Holger. 1999b. The morphosyntax of demonstratives in synchrony and diachrony. Linguistic Typology 3(1). 1-49.

Diessel, Holger. 2006. Demonstratives, joint attention, and the emergence of grammar. Cognitive Linguistics 17. 463-489.

Dixon, R.M.W. 2003. Demonstratives: A cross-linguistic typology. Studies in Language 27. 62112.

Ebert, Karen H. 1997. A grammar of Athpare. München: LINCOM.

Enfield, Nick J. 2003. Demonstratives in space and interaction: Data from Lao speakers and implications for semantic analysis. Language 79. 82-117.

Enfield, Nick J. 2009. The anatomy of meaning: Speech, gesture, and composite utterances. Cambridge: Cambridge University Press.

Epps, Patience. 2008. A grammar of Hup. Berlin/New York: Mouton de Gruyter.

Epps, Patience. 2009. Escape from the noun phrase. From relative clause to converb and beyond in an Amazonian language. Diachronica 26(3). 87-318.

Evans, Nicholas. 2007. Insubordination and its uses. In Irina Nikolaeva (ed.), Finiteness: Theoretical and empirical foundations, 366-431. Oxford: Oxford University Press.

Evans, Nicholas. 2010. The grammar of expectation. Handout from a seminar at Ludwig-Maximilians Universität, Munich, 8 January.

Faller, Martina. 2004. The deictic core of "non-experienced past" in Cuzco Quechua. Journal of Semantics 21(1). 45-85.

Fleck, David. 2003. A grammar of Matses. Rice University dissertation.

Fillmore, Charles J. 1997. Lectures on deixis. Stanford, CA: CSLI Publications.

Genetti, Carol. 2007. A grammar of Dolakha Newar. Berlin/New York: Mouton de Gruyter.

Genetti, Carol. 2011. Nominalisation in Tibeto-Burman languages of the Himalayan area: A typological perspective. In Foong Ha Yap, Karen Grunow-Hårsta and Janick Wrona (eds.), Nominalization in Asian languages: Diachronic and typological perspectives, 163-193. Amsterdam/Philadelphia: John Benjamins.

Genetti, Carol, Ellen Bartee, Alec Coupe, Kristine Hildebrandt and You-Jing Lin. 2008. Syntactic aspects of nominalization in five Tibeto-Burman languages of the Himalayan area. Linguistics of the Tibeto-Burman Area 31(2). 97-144. 
Gildea, Spike. 1993. The development of tense markers from demonstrative pronouns in Panare (Cariban). Studies in Language 17(1). 53-73.

Haan, Johnson Welem. 2001. The grammar of Adang: a Papuan language spoken on the island of Alor, East Nusa Tenggara, Indonesia. Sydney: University of Sydney dissertation.

de Haan, Ferdinand. 2008. Evidentiality in Athabaskan. Coyote Papers: Working Papers in Linguistics, Linguistic Theory at the University of Arizona 16. 67-82.

Haig, Geoffrey. 2011. Linker, relativizer, nominalizer, tense-particle: On the Ezafe in West Iranian. In Foong Ha Yap, Karen Grunow-Hårsta and Janick Wrona (eds.), Nominalization in Asian Languages: Diachronic and Typological Perspectives, 363-390. Amsterdam/ Philadelphia: John Benjamins.

Haiman, John, 1978. Conditionals are topics. Language 54. 564-589.

Hanks, William. 1990. Referential practice: Language and lived space among the Maya. Chicago: University of Chicago Press.

Hanks, William. 1992. The indexical ground of deictic reference. In Alessandro Duranti and Charles Goodwin (eds.), Rethinking context, 43-77. Cambridge: Cambridge University Press.

Hanks, William. 2005. Explorations in the deictic field. Current Anthropology 46. 191-220.

Hanks, William. 2009. Fieldwork on deixis. Journal of Pragmatics 41(1). 10-24.

Hargreaves, David. 2005. Agency and intentional action in Kathmandu Newar. Himalayan Linguistics Journal 5. 1-48.

Haspelmath, Martin. 1997. From space to time: Temporal adverbials in the world's languages. München: LINCOM.

Hildebrandt, Kristine. 2004. A grammar and glossary of the Manange language. In Carol Genetti (ed.), Tibeto-Burman languages of Nepal: Manange and Sherpa, 3-189. Canberra: Pacific Linguistics.

Himmelmann, Nikolaus P. 1997. Deiktikon, Artikel, Nominalphrase: Zur Emergenz syntaktischer Struktur. Tübingen: Niemeyer.

Holton, Gary. 2007. Spatial orientation in Western Pantar (Lamma). Paper presented at the East Nusantara Conference. Kupang, August 1-3.

Horie, Kaoru. 2008. The grammaticalisation of nominalisers in Japanese and Korean: A contrastive study. In Maria Jose Lopez-Couso and Elena Seoane (eds.), Rethinking grammaticalisation: New perspectives, 169-187. Amsterdam/Philadelphia: John Benjamins.

Horie, Kaoru. 2011. Versatility of nominalisations: Where Japanese and Korean contrast. In Foong Ha Yap, Karen Grunow-Hårsta and Janick Wrona (eds.), Nominalization in Asian languages: Diachronic and typological perspectives, 473-496. Amsterdam/Philadelphia: John Benjamins.

Kirsner, Robert. 1979. Deixis in discourse: An exploratory quantitative study of modern Dutch demonstrative adjectives. In Talmy Givon (ed.), Syntax and semantics, Volume 3, 355-375. New York: Academic Press.

Klamer, Marian. 2010. A grammar of Teiwa. Berlin/New York: Mouton de Gruyter.

Kratochvíl, František. 2007. A grammar of Abui: A Papuan language of Alor. Utrecht: LOT Publications.

Kratochvíl, František. No date. Corpus of the Abui language. Singapore, Nanyang Technological University.

Kratochvíl, František. 2011. Discourse-structuring functions of Abui demonstratives. In Foong Ha Yap, Karen Grunow-Hårsta and Janick Wrona (eds.), Nominalization in Asian 
languages: Diachronic and typological perspectives, 757-788. Amsterdam/Philadelphia: John Benjamins.

Küntay, Aylin and Özyürek, Asli. 2006. Learning attentional contrasts in using demonstratives in conversation: What do language-specific strategies in Turkish reveal? Journal of Child Language 33. 303-320.

Landaburu, Jon. 2007. La modalisation du savoir en langue andoke (Amazonie colombienne). In Zlatka Guentchéva and Jon Landaburu (eds.), L'Énonciation médiatisée II, 23-48. París/ Leuven: Peeters.

Loughnane, Robyn. 2009. A grammar of Oksapmin. University of Melbourne dissertation.

Matisoff, James A. 1972. Lahu nominalisation, relativisation, and genetivisation. In John P. Kimball (ed.), Syntax and semantics, Volume 1, 237-257. New York: Academic Press.

Michaelis, Laura A. 2001. Exclamative constructions. In Martin Haspelmath, Ekkehard König, Wolf Oesterreicher and Wolfgang Raible (eds.), Language typology and language universals, Volume 2, 1038-1050. Berlin/New York: Mouton de Gruyter.

Mithun, Marianne. 1999. The languages of Native North America. Cambridge: Cambridge University Press.

Noonan, Michael. 1997. Versatile nominalizations. In Joan Bybee, John Haiman and Sandra A. Thompson (eds.), Essays on language function and language type, 373-394. Amsterdam/ Philadelphia: John Benjamins.

Noonan, Michael. 2006. Direct speech as a historical style in Chantyal. Himalayan Linguistics 6. $1-32$.

Noonan, Michael, Ram Prasad Bhulanja, Jag Man Chhantyal and William Pagliuca. 1999. Chantyal dictionary and texts. Berlin/New York: Mouton de Gruyter.

Özyürek, Asli. 1998. An analysis of the basic meaning of Turkish demonstratives in face-to-face conversational interaction. In Isabelle Guaïtella, Serge Santi, Christian Cave and Gabrielle Konopczynski (eds.), Oralité et Gestualité: Communication multimodale, interaction. Paris: L'Harmattan.

Pitkin, Harvey. 1984. Wintu grammar. Berkeley: University of California Press.

Piwek, Paul, Robbert-Jan Beun and Anita Cremers. 2007. 'Proximal' and 'distal' in language and cognition: Evidence from deictic demonstratives in Dutch. Journal of Pragmatics 40(4). 694-718.

Potsdam, Eric. 2011. Expressing exclamatives in Malagasy. In Foong Ha Yap, Karen GrunowHårsta and Janick Wrona (eds.), Nominalization in Asian languages: Diachronic and typological perspectives, 659-683. Amsterdam/Philadelphia: John Benjamins.

Rasoloson, Janie and Carl Rubino. 2005. Malagasy. In Alexander Adelaar and Nikolaus P. Himmelmann (eds.), The Austronesian languages of Asia and Madagascar, 456-488. London/ New York: Routledge.

Reesink, Ger P. 1987. Structures and their functions in Usan. Amsterdam/Philadelphia: John Benjamins.

Reesink, Ger P. 1994. Domain-creating constructions in Papuan languages. In Ger P. Reesink (ed.), Topics in descriptive Papuan linguistics, 98-121. Leiden: Vakgroep Talen en Culturen van Zuidoost-Azië en Oceanië, Rijksuniversiteit te Leiden.

Salanova, Andrés Pablo. 2006. The sense of Mebengokre nominalizations. In Atsushi Fujimori and Maria Amelia Reis Silva (eds.), Proceedings of the 11th Workshop on Structure and Constituency of the Languages of the Americas. UBC Working Papers in Linguistics.

San Roque, Lila. 2008. An introduction to Duna grammar. Australian National University dissertation. 
Schapper, Antoinette. 2010. Bunaq, a Papuan language of central Timor. Australian National University dissertation.

Schuh, Russell G. 1983. Kilba equational sentences. Studies in African Linguistics 14. 311-326.

Simpson, Andrew. 2008. The grammaticalisation of clausal nominalisers in Burmese. In María José López-Couso and Elena Seoane (eds.), Rethinking grammaticalisation. New perspectives, 265-288. Amsterdam/Philadelphia: John Benjamins.

Simpson, Andrew and Zoe Wu. 2001. The grammaticalisation of formal nouns and nominalisers in Chinese, Japanese and Korean. In Thomas E. McAuley (ed.), Language change in East Asia, 250-283. London: Curzon.

Steinhauer, Hein. 1990. Demonstratives in the Blagar language of Dolop (Pura, Alor, Indonesia). In Tom Dutton (ed.), Papers in Papuan Linguistics, No. 1, 179-223. Canberra: Pacific Linguistics.

Traugott, Elizabeth. 1975. Spatial expressions of tense and temporal sequencing: A contribution to the study of semantic fields. Semiotica 15(3). 207-30.

Vries, Lourens de. 1995. Demonstratives, referent identification and topicality in Wambon and some other Papuan languages. Journal of Pragmatics 24(5). 513-533.

Vries, Lourens de. 2006. Areal pragmatics of New Guinea: Thematisation, distribution and recapitulative linkage in Papuan narratives. Journal of Pragmatics 38(6). 811-828.

Woodbury, Tony. 1985. The functions of rhetorical structure: A study of Central Alaskan Yupik Eskimo discourse. Language in Society 14. 153-190.

Yap, Foong Ha. 2011. Referential and non-referential uses of nominalization constructions in Malay. In Foong Ha Yap, Karen Grunow-Hårsta and Janick Wrona (eds.), Nominalization in Asian languages: Diachronic and typological perspectives, 627-658. Amsterdam/Philadelphia: John Benjamins.

Yap, Foong Ha, Stephen Matthews, and Kaoru Horie. 2004. From pronominalizer to pragmatic marker: Implications for unidirectionality from a crosslinguistic perspective. In Olga Fischer, Muriel Norde and Harry Perridon (eds.), Up and down the cline: The nature of grammaticalization, 137-168. Amsterdam/Philadelphia: John Benjamins.

Yap, Foong Ha and Karen Grunow-Hårsta. 2010. Non-referential uses of nominalization constructions: Asian perspectives. Language and Linguistics Compass 3(1). 1-21.

Yap, Foong Ha, Karen Grunow-Hårsta and Janick Wrona. 2011. Introduction: Nominalization strategies in Asian languages. In Foong Ha Yap, Karen Grunow-Hårsta and Janick Wrona (eds.), Nominalization in Asian languages: Diachronic and typological perspectives, 1-57. Amsterdam/Philadelphia: John Benjamins.

\section{Author' addresses}

Antoinette Schapper

Leiden University Centre for Linguistics

Postbus 9515

NL-2300 RA Leiden

Netherlands

a_schapper@hotmail.com
Lila San Roque

Max Planck Institute for Psycholinguistics

Postbus 310

6500 AH Nijmegen

Netherlands

lila.san.roque@gmail.com 